Review

\title{
Discovering the role of mitochondria in the iron deficiency-induced metabolic responses of plants
}

\author{
Gianpiero Vigani* \\ Dipartimento di Produzione Vegetale, Università degli Studi di Milano, Via Celoria 2, 20133 Milano, Italy
}

\section{A R T I C L E I N F O}

\section{Article history:}

Received 16 June 2011

Received in revised form

14 September 2011

Accepted 14 September 2011

\section{Keywords:}

Energy metabolism

Fe deficiency

Tricarboxylic acid (TCA) cycle

Mitochondria

Respiratory chain

\begin{abstract}
A B S T R A C T
In plants, iron (Fe) deficiency-induced chlorosis is a major problem, affecting both yield and quality of crops. Plants have evolved multifaceted strategies, such as reductase activity, proton extrusion, and specialised storage proteins, to mobilise Fe from the environment and distribute it within the plant. Because of its fundamental role in plant productivity, several issues concerning Fe homeostasis in plants are currently intensively studied. The activation of Fe uptake reactions requires an overall adaptation of the primary metabolism because these activities need the constant supply of energetic substrates (i.e., NADPH and ATP). Several studies concerning the metabolism of Fe-deficient plants have been conducted, but research focused on mitochondrial implications in adaptive responses to nutritional stress has only begun in recent years. Mitochondria are the energetic centre of the root cell, and they are strongly affected by Fe deficiency. Nevertheless, they display a high level of functional flexibility, which allows them to maintain the viability of the cell. Mitochondria represent a crucial target of studies on plant homeostasis, and it might be of interest to concentrate future research on understanding how mitochondria orchestrate the reprogramming of root cell metabolism under Fe deficiency. In this review, I summarise what it is known about the effect of Fe deficiency on mitochondrial metabolism and morphology. Moreover, I present a detailed view of the possible roles of mitochondria in the development of plant responses to Fe deficiency, integrating old findings with new and discussing new hypotheses for future investigations.
\end{abstract}

(c) 2011 Elsevier GmbH. All rights reserved.

\section{Contents}

Introduction.

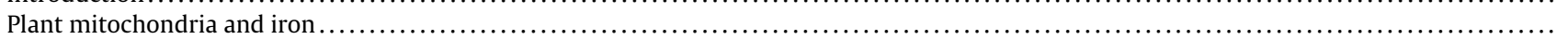

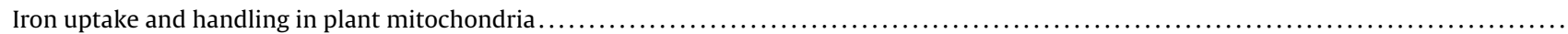

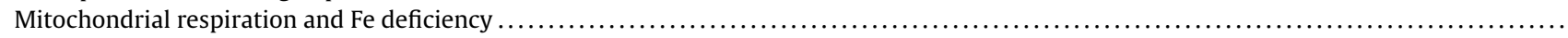

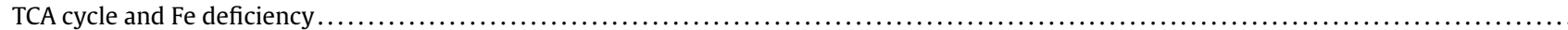

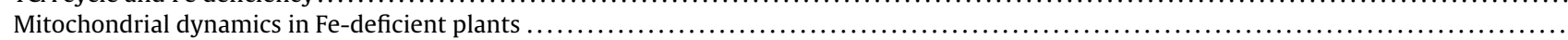

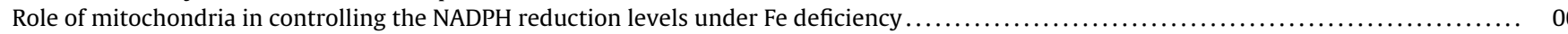

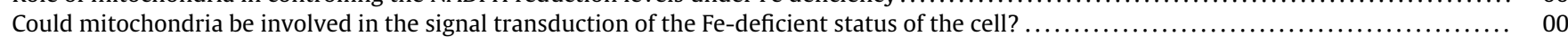

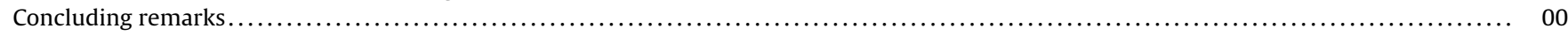

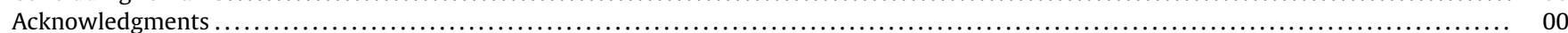

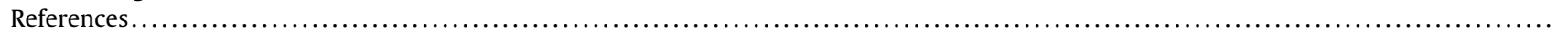
. .

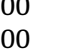

\section{Introduction}

Iron (Fe) is an essential element for all living organisms because it is a cofactor for fundamental biochemical activities, such as

Abbreviations: $\mathrm{mETC}$, mitochondrial electron transport chain; $\mathrm{ND}_{\mathrm{in}}$, internal type II NADPH dehydrogenases; $\mathrm{ND}_{\mathrm{ex}}$, external type II NADPH dehydrogenases.

* Tel.: +39 0250316522; fax: +390250316521.

E-mail address: gianpiero.vigani@unimi.it energy metabolism, oxygen transport and DNA synthesis. Because of its redox reactivity [Fe shuttles between the reduced ferrous $\left(\mathrm{Fe}^{2+}\right)$ and the oxidised ferric $\left(\mathrm{Fe}^{3+}\right)$ forms], which allows it to associate with proteins and bind to oxygen, Fe transfers electrons and mediates catalytic reactions (Aisen et al., 2001). Fe is also potentially toxic because it can catalyse the propagation of reactive oxygen species (ROS) and the generation of highly reactive radicals (such as the hydroxyl radical) through Fenton chemistry (Koppenol, 1993). The ensuing oxidative stress is associated with damage to cellular macromolecules, tissue injury and

0176-1617/\$ - see front matter @ 2011 Elsevier GmbH. All rights reserved. doi:10.1016/j.jplph.2011.09.008 


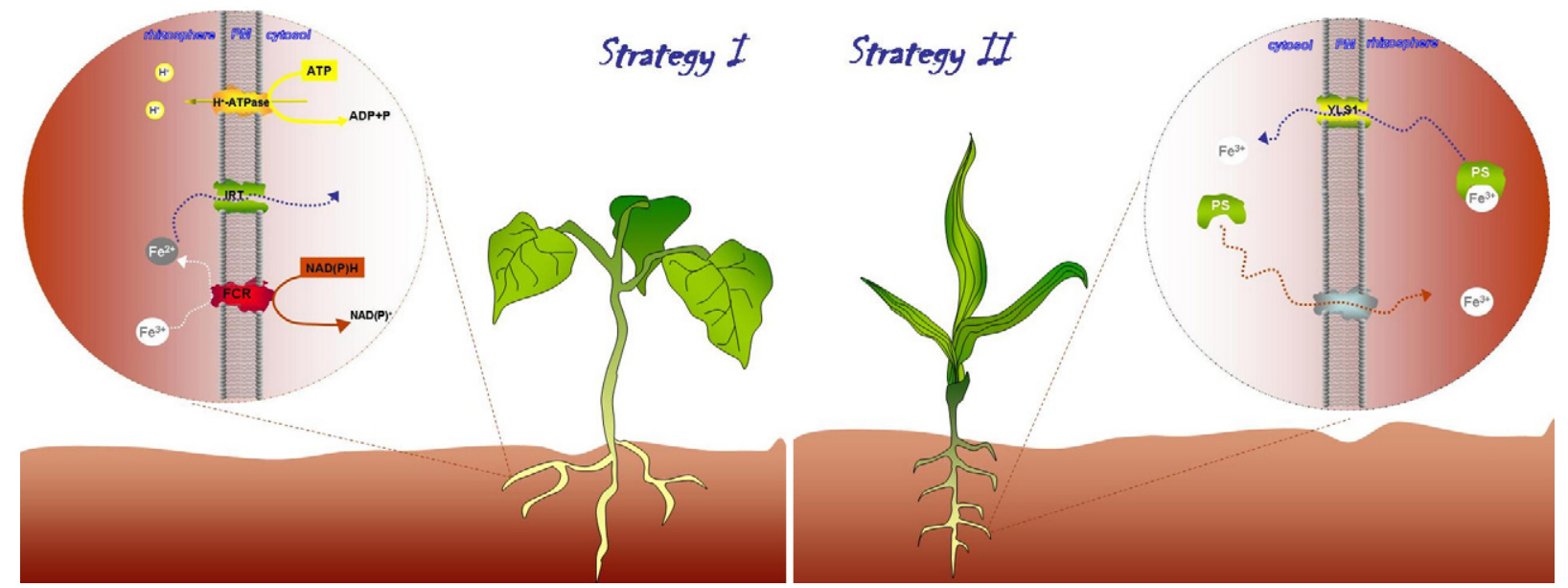

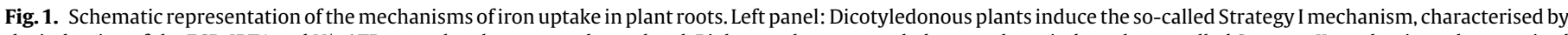

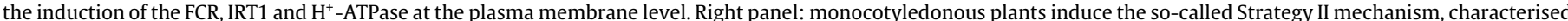

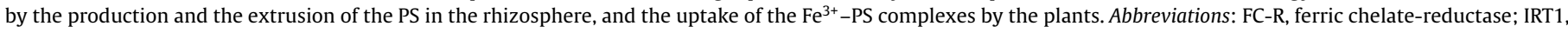
iron-regulated transporter; PM, plasma membrane; PSs, phytosiderophores; YSL1, yellow strip-like 1.

disease (Galaris and Pantopoulos, 2008; Kell, 2009). Notably, the bioavailability of oxidised $\mathrm{Fe}^{3+}$ is poor due to the limited solubility of its compounds. Thus, the acquisition, usage and detoxification of Fe poses a considerable challenge for cells and organisms, which have evolved sophisticated mechanisms to satisfy their metabolic needs and, concomitantly, minimise the risk of toxicity (Andrews, 2008; De Domenico et al., 2008; Hentze et al., 2010). In plants, most of the concern about Fe nutrition is related to its low availability in soil solutions. In fact, notwithstanding its abundance, Fe exists in well-aerated soils as scarcely soluble oxides and oxyhydroxides and is therefore not freely available for plant uptake. To cope with this problem, plants have developed two main strategies: graminaceous plants use a chelation-based strategy (Strategy II), whereas the majority of plants, dicotyledons and non-graminaceous monocotyledons, use a reduction-based strategy (Strategy I) (Schmidt, 1999; Curie and Briat, 2003; Abadía et al., 2011) (Fig. 1). The chelation-based mechanism (Strategy II) has evolved in grasses, which includes most of the world's staple grain crops. Grasses produce molecules of the mugineic acid family called phytosiderophores (PSs). The PSs form a stable, hexadentate complex with $\mathrm{Fe}^{3+}$, which is the predominant form of $\mathrm{Fe}$ found in aerobic soils. PSs are secreted into the rhizosphere where they chelate and help to solubilise $\mathrm{Fe}^{3+}$. The Fe (III)-PS complex is then absorbed by the root cells through the action of Yellow Stripe1 (YS1) proteins (von Wiren et al., 1999; Curie et al., 2001; Abadía et al., 2011) (Fig. 1, right panel). In Strategy I, Fe acquisition is mediated by a reduction-based mechanism: a ferric chelate reductase (FCR) converts Fe (III)-chelates to Fe (II), and an iron regulated transporter (IRT1) moves the ion across the plasma membrane (PM) into the cell. Additionally, in most of the Strategy I plants studied to date, there is an associated increase in the activity at the PM, i.e., $\mathrm{H}^{+}$ATPase transports ions across the membrane, which lowers the $\mathrm{pH}$ of the growth medium, increases the Fe solubility and generates the electrochemical proton gradient necessary to drive ion uptake (Rabotti and Zocchi, 1994; Dell'Orto et al., 2000; Santi et al., 2005; Santi and Schmidt, 2008, 2009) (Fig. 1, left panel). The genes encoding these enzymes have been identified in several plants (Eide et al., 1996; Robinson et al., 1999; Eckhardt et al., 2001; Waters et al., 2002, 2007; Santi et al., 2005). Additionally, in Strategy I plants a plethora of organic compounds, including carboxylates, phenolics, and flavonoids, are increased under Fe deficiency (Cesco et al., 2010; Tomasi et al., 2008).

Under Fe-limited growth conditions, the induction of the Strategy I mechanism is not restricted to the activation of FCR, IRT1 and $\mathrm{H}^{+}$-ATPase. A metabolic reprogramming of plant root cells is necessary; the activation of reduction processes and the enhanced proton extrusion require an adequate energy supply in the form of NADPH and ATP. The recharging of such substrates requires the acceleration of the metabolism that is strictly linked to energy production (Zocchi, 2006; Vigani and Zocchi, 2009). In fact, several papers published in the last 30 years revealed that almost all enzymes belonging to the glucose catabolism, mainly at the glycolysis level, are increased in several Strategy I plants (Table 1). Among the metabolic activities that increase in Fe-deficient plants, phosphoenolpyruvate carboxylase (PEPC) is one of the most important (see references in Table 1). PEPC is a ubiquitous enzyme in plants that catalyses the fixation of bicarbonate to phosphoenolpyruvate (PEP) to produce oxaloacetate (OAA) and Pi. To maintain an

Table 1

Experimental evidences about the increase of some cytosolic enzymes of glucose catabolism under Fe deficiency in several Strategy I plants. References are tabulated according to the type of induction (activity and/or protein content and/or transcript) observed under Fe deficiency with regard the specific enzyme. The numbering of references is specified below.

\begin{tabular}{llll}
\hline Enzyme & Activity & Protein & Transcript \\
\hline HK & 7 & & \\
PGI & & & \\
ATP-PFK & $5 ; 7 ; 11 ; 12$ & $14 ; 15$ & \\
PP-PFK & & 14 & \\
F1,6BPA & & $8 ; 13 ; 14 ; 15$ & 6 \\
G3PDH & $1 ; 2 ; 5 ; 11 ; 12$ & $12 ; 13 ; 15$ & 6 \\
TPI & & $8 ; 13$ & 6 \\
PGK & & $13 ; 14$ & 6 \\
PGM & & $8 ; 14 ; 15$ & 6 \\
Enolase & & $8 ; 13 ; 14 ; 15$ & 6 \\
PK & $5 ; 7 ; 11 ; 12$ & & 6 \\
PEPC & $2 ; 3 ; 4 ; 7 ; 9 ; 10 ; 11 ; 12 ; 16$ & $3 ; 8 ; 16$ & $6 ; 10 ; 17$ \\
G6PDH & $1 ; 2 ; 4 ; 11 ; 12$ & $14 ; 15$ & \\
\hline
\end{tabular}

(1) Sijmons and Bienfait (1983); (2) Rabotti et al. (1995); (3) De Nisi and Zocch (2000); (4) López-Millán et al. (2000a,b); (5) Espen et al. (2000); (6) Thimm et al. (2001); (7) Zocchi et al. (2007); (8) Li et al. (2008); (9) López-Millán et al. (2009); (10) Andaluz et al. (2009); (11) M'Sehli et al. (2008); (12) Jelali et al. (2010); (13) Rellán-Álvarez et al. (2010); (14) Donnini et al. (2010); (15) Rodríguez-Celma et al (2011); (16) Slatni et al. (2011); (17) De Nisi et al. (2010). Abbreviations: ATP-PFK, ATP-dependent phosphofructokinase; F1,6BPA, fructose 1,6-bisphosphate aldolase; G6PDH, glucose-6-phosphate dehydrogenase; GAPDH, glyceraldehyde 3-phosphate dehydrogenase; HK, hexokinase; PEPC, phosphoenolpyruvate carboxylase; PGI, phosphoglucoisomerase; PGK, phosphoglycerate kinase; PGM, phosphoglycerate mutase; PK, pyruvate kinase; PP-PFK, PP-dependent phosphofructokinase; TPI, triosephosphate isomerise. 
adequate rate of glycolysis, PEP must be consumed at a high rate. Under conditions of Fe deficiency, it has been postulated that the activation of PEPC could be the downstream driving force for glycolysis that leads to an increase in the rate and production of cytosolic acidification to activate $\mathrm{H}^{+}$-ATPase (Zocchi, 2006). Additionally, the activation of PEPC could be responsible for the production of organic acids. Indeed, when under Fe deficiency, plants produce considerable amounts of organic acids, mainly citrate and malate (Abadía et al., 2002 and references therein). The following is a list of potential role(s) of increased organic acids under Fe deficiency: (i) to control the cytosolic $\mathrm{pH}$ or feed the increased activity of $\mathrm{H}^{+}$ATPase at the PM; (ii) to increase production of oxalacetate (as a product of PEPC) and/or malate to replenish the tricarboxylic acid (TCA) cycle; and/or (iii) to facilitate the acquisition of Fe from the soil by the root cell (Abadía et al., 2002).

Overall, the upregulation of glycolysis under Fe deficiency provides: (i) ATP synthesis to sustain the major activity of the $\mathrm{H}^{+}$ATPase; (ii) the formation of reducing equivalents for the FC-R; (iii) the formation of PEP and (iv) a contribution to the regulation of cytosolic $\mathrm{pH}$. Because Fe deficiency induces an energy demand in the cell, it is critical to understand how this stress affects mitochondria.

\section{Plant mitochondria and iron}

Mitochondria play a key role in energy transduction, and are the site of aerobic respiration, a process common to almost all eukaryotic organisms that releases a large amount of free energy in the cell. Mitochondria possess two membranes that divide the organelle into four compartments: (i) the outer membrane (OMM); (ii) the region between the two membranes or intermembrane space (IMS); (iii) a highly invaginated inner membrane (IMM); and (iv) the matrix, which is the aqueous phase contained within the inner membrane (Sweetlove et al., 2007). The IMM is the site of oxidative phosphorylation (OXPHOS) electron transport chain coupling NADH and $\mathrm{FADH}_{2}$ oxidation, and reduction of oxygen, to proton translocation and OXPHOS. The TCA cycle, which is responsible for the oxidative decarboxylation of organic acids leading to reduction of NADP and FAD and substrate-level phosphorylation of ADP to ATP, takes place in the matrix (Millar et al., 2011 and references therein).

The mitochondrion occupies a central place in the metabolic network of eukaryotes. Essential metabolic processes occur within the organelle, and several other metabolic pathways either converge on or derive from the mitochondrion. In plants, mitochondria provide precursors for a number of essential biosynthetic processes (e.g., nitrogen fixation and the biosynthesis of amino acids, tetrapyrroles and vitamin cofactors, Douce, 1985; Douce and Neuberger, 1989; Mackenzie and McIntosh, 1999).

Interestingly, mitochondria are also a focal point of $\mathrm{Fe}$ metabolism. An analysis of the metallome of mitochondria isolated from Arabidopsis revealed a 26:8:6:1 molar ratio for iron:zinc:copper:manganese (Tan et al., 2010), suggesting that Fe is the primary micronutrient present in the mitochondrion (Nouet et al., 2011). Mitochondria contain a large amount of metalloproteins that require Fe to carry out their function (Bertini and Rosato, 2007). In fact, several enzymes belonging to both the respiratory chain and to the TCA cycle are Fe-containing proteins. Moreover, crucial steps of the Fe-S cluster assembly for the entire cell take place in the mitochondria, suggesting an important role for this compartment in Fe handling by the cell.

Iron deficiency and mitochondria are strongly linked because this stress greatly induces the Strategy I activities that lead to a great energy demand, thus the participation of the mitochondria would be required.

\section{Iron uptake and handling in plant mitochondria}

Once inside the root cell, Fe can face different fates: (i) chelation by citrate and stored in vacuole or transported to the shoot; (ii) sequestration by ferritin in the cytosol; or (iii) transportation to organelles, such as mitochondria (Conte and Walker, 2011). The processes of Fe transport into plant mitochondria are partially unknown. The OMM permeability is conferred by a family of porin proteins, forming channels for the free diffusion of a wide range of molecules, and no specific Fe transporter has been identified so far. In the IMM, the Fe importer MIT1 (Mitochondrial Iron Transporter 1) has been recently identified, which is essential for plant growth and development (Bashir et al., 2011). Furthermore, the ABC transporter STA1/AtATM3 (ATP-binding cassette Transporters of Mitochondria 3) has been characterised in Arabidopsis and implicated in the export of Fe-S clusters (Kushnir et al., 2001). In addition, FCR(s), encoded by FRO genes in plants, might be involved in mitochondrial Fe transport because AtFRO3 and AtFRO8 contain mitochondria-targeting sequences and are mainly located in root and shoot veins, respectively (Mukherjee et al., 2006). These findings suggest that a reduction-based uptake could also take place in the IMM of mitochondria. Moreover, the oxidising conditions found in the mitochondrial IMS (Hu et al., 2008) would indicate the need for a reduction-based mechanism (Abadía et al., 2011).

Once $\mathrm{Fe}$ is inside the mitochondria, it can be utilised in several pathways. The most important pathways for mitochondrial functionality and cell viability are Fe-S cluster assembly, haem biosynthesis and Fe storage.

Iron-sulphur (Fe-S) clusters are cofactors that are chemically simple but functionally versatile. In fact, they represent a prosthetic group of proteins that are essential to life processes, such as photosynthesis, respiration and nitrogen fixation. Fe-S clusters consist of Fe and acid-labile sulphide (Balk and Lobréaux, 2005). Plant mitochondria operate the so-called ISC (Iron Sulphur Cluster) pathway for the assembly of the Fe-S cluster. Recently, this pathway was extensively reviewed (Balk and Pilon, 2011). Interestingly, the Fe-S cluster assembly capability of plant mitochondria is essential not only for mitochondrial $\mathrm{Fe}-\mathrm{S}$ proteins but also for cytosolic Fe-S protein synthesis. Indeed, in the cytosol, the socalled Cytosolic Iron-sulphur protein Assembly (CIA) machinery is present. Cytosolic Fe-S protein synthesis depends on ISC components and a mitochondrial ABC transporter (ATM3) that has been proposed to export an unidentified product of the ISC pathway, allowing Fe-S cluster assembly and therefore Fe-S protein synthesis in the cytosol by the CIA machinery (Balk and Pilon, 2011 and references therein).

There is also evidence that mitochondria can synthesise haem. Haem is a prosthetic group formed by an Fe atom that coordinates the binding of a large heterocyclic organic ring called a porphyrin. Not all porphyrins contain Fe, but a substantial fraction of porphyrin-containing metalloproteins has haem as their prosthetic group: the so-called haemoproteins. Haem forms the prosthetic group of photosynthetic and respiratory cytochromes involved in energy transduction and oxidases, such as catalase, peroxidase and NADPH oxidase (Sweetlove et al., 2007 and references therein). In plant cells, the presence of the haem biosynthetic pathway in plant mitochondria is still a matter of debate. However, some authors report that the enzymes that catalyse the final steps of haem biosynthesis, such as ferrochelatase (which catalyses the insertion of ferrous Fe into protoporphyrin IX) and protoporphyrinogen oxidase, are also present mitochondria and in plastids (Sweetlove et al., 2007 and references therein).

The mitochondrial proteins that are critical for Fe homeostasis are ferritin and frataxin. Generally, ferritin is considered the primary Fe storage protein in the cell. Ferritin provides protection against Fe toxicity and oxidative damage, and its expression is 
increased upon exposure to an excess of Fe (Eisenstein, 2000; Arosio et al., 2009; Briat et al., 2010a,b). Zancani et al. (2004) reported the mitochondrial localisation of ferritin in both Pisum sativus and Arabidopsis thaliana. Moreover, recently, the ferritin isoform FER4 was identified in the mitochondria in Arabidopsis heterotrophic cells (Tarantino et al., 2010b). A fer4 Arabidopsis mutant displays different rearrangements of its respiratory machinery but is not impaired in its development or response to abiotic stress (Tarantino et al., 2010a,b). Although the precise role of ferritin in plant mitochondria has not been resolved completely, there is evidence for its role in Fe homeostasis. Frataxin is a conserved mitochondrial protein implicated in cellular Fe homeostasis, which functions as an Fe chaperone that delivers Fe for the Fe-S cluster and haem biosynthesis (Malinardi et al., 2011 and references therein). Frataxin deficiency causes severe disease in both humans and plants; the absence of frataxin induces severe oxidative stress in mitochondria, while its overexpression allows the cell to be more resistant to oxidising agents (Møller et al., 2011 and references therein).

Overall, it is increasingly evident that mitochondria can be considered as an 'iron-handling area' within the cell, possessing several specific enzymes for the maintenance of this element. Mitochondria store and process Fe to synthesise a large number of essential proteins for their own functionality and for that of the entire cell.

\section{Mitochondrial respiration and Fe deficiency}

In the mitochondria of all eukaryotes, the principal respiratory electron transport chain consists of a series of membrane-bound redox centres that catalyse the multi-step transfer of electrons from $\mathrm{NADH}$ and $\mathrm{FADH}_{2}$ to oxygen. The mitochondrial electron transfer chain (mETC) facilitates a number of exergonic redox reactions and conserves energy through proton translocation. The standard mETC consists of four multi-centred protein complexes (referred to as Complexes I through IV). In addition, the $\mathrm{F}_{1} \mathrm{~F}_{0}$-ATP synthase (Complex V), which does not have electron transfer activity, provides a path for passive proton diffusion into the matrix and uses the free energy released by this spontaneous movement to drive the phosphorylation of ADP. In addition to the electron transfer chain shared by all aerobic eukaryotes, plant mitochondria also possess novel pathways for both the oxidation of NADH and the reduction of oxygen. These bypass proteins, the so-called alternative type II NADPH dehydrogenases [located both in the external surface of the IMM $\left(N D_{e x}\right)$ and the internal surface of the IMM $\left.\left(N D_{\text {in }}\right)\right]$ and the alternative oxidase (AOX), do not pump protons, and the free energy released as electrons flow through them is lost as heat. These additional enzymes allow a great deal of flexibility in the oxidation of NADPH in plants. Type II NADPH dehydrogenases reduce ubiquinone and thus circumvent respiratory Complex I, whereas AOX bypasses Complexes III and IV of the cytochrome pathway by directly oxidising ubiquinol. Millar et al. (2011) recently reviewed the specific molecular and genetic features of each enzyme of the respiratory chain.

In the absence of Fe, the levels of some Fe-containing components (cytochromes and Fe-S clusters) were greatly diminished in the mitochondria of Fe-deficient sycamore cells (Pascal and Douce, 1993) and cucumber roots (Vigani et al., 2009). In Fedeficient sycamore cells, the activity of Complex II was affected, whereas Complexes I, III, and IV, and ATP synthase, were unimpaired. In contrast, in cucumber root, the number of Fe ions required for the correct assembly of each mETC complex (unit) and their relative activities under Fe-deficient conditions are highly correlated: Complex IV, which has only two Fe atoms, showed a decrease in activity of approximately $50 \%$, whereas Complexes I and II, which require at least 20 and 10 Fe atoms, respectively, showed a greater decrease ( $95 \%$ and $77 \%$, respectively). A proteomic investigation of Medicago truncatula roots under Fe deficiency showed a decreased level of some Fe-containing proteins related to the respiratory chain (e.g., $76 \mathrm{kDa}$ mitochondrial Complex I) (Rodríguez-Celma et al., 2011). In contrast, a proteomic study performed on Fe-deficient Arabidopsis roots showed an increased level of several proteins belonging to the respiratory chain. These proteins included cytochrome $c$ oxidase, the ubiquinol-cytochrome $c$ reductase complex ubiquinone-binding protein and three components of mitochondrial Complex I (Lan et al., 2011). The contrasting results obtained in cucumber compared with Arabidopsis might be explained by the different degree of Fe deficiency conditions used in the studies.

Overall, root mitochondria are strongly affected by Fe starvation because they require at least forty $40 \mathrm{Fe}$ atoms per respiratory unit to function (Vigani et al., 2009). Nevertheless, when Fe availability is low, either due to absence, as in the cucumber study, or low supply (Fe content in the nutrient solution is low but not zero), as in the Arabidopsis (Lan et al., 2011) and sycamore cell (Pascal and Douce, 1993) studies, the mitochondria are still working.

Under increased Fe deficiency, it is possible to observe an interesting regulation of the respiratory chain in cucumber root; the dehydrogenase pathways (the enzymes able to reduce the UQ pool) of the mETC are more affected with respect to the cytochrome pathways (the enzymes able to oxidase the UQ pool). The strong decrease of Complex I and Complex II activities in the absence of Fe is compensated by the activation of the type II alternative NADPH dehydrogenase (see above). In fact, both the enzymatic activity and the protein level of the $\mathrm{ND}_{\mathrm{ex}}$ are highly induced compared with the $\mathrm{ND}_{\text {in }}$ (Vigani and Zocchi, 2010). These findings suggest that the respiratory chain could contribute to cytosolic NADPH turnover through the $\mathrm{ND}_{\mathrm{ex}}$, notwithstanding that the mETC is strongly inhibited by Fe deficiency (Vigani and Zocchi, 2010). Accordingly, Higa et al. (2010) observed an induction of type II alternative NADPH dehydrogenase in the Fe-deficient roots of Hyoscyamus albus that was similar to that in cucumber, where low Fe availability decreases the main dehydrogenase enzymes of the mETC (Complexes I and II) and induces the alternative dehydrogenase pathways. Interestingly, Higa and co-workers (2010) stated that Complex I and Complex II require not only a large number of Fe ions but also flavins as cofactors. Interestingly, flavin accumulation and excretion are induced upon Fe deprivation in various plant species (Pound and Welkie, 1958; Nagarajah and Ulrich, 1966; Kannan, 1988; Welkie et al., 1990). It has been suggested that flavins, which accumulate in Fe-deficient roots, could act as electron donors or as cofactors for the FCR (Rodríguez-Celma et al., 2011; López-Millán et al., 2000a,b; Gonzalez-Vallejo et al., 1998; Welkie and Miller, 1993) because this enzyme contains an FAD-binding sequence motif (Schagerlof et al., 2006). However, it is rational to consider that if Complex I and Complex II proteins were prevented from becoming fully functional by Fe deficiency, the unused flavins might be transported outside the mitochondria, reaching the apoplast and the rhizosphere (Higa et al., 2010).

Generally, Fe deficiency affects the respiratory chain by limiting the activity of Fe-containing enzymes and inducing the alternative enzymes. This regulation allows the respiratory chain to partially satisfy the energy demand of the cell.

\section{TCA cycle and Fe deficiency}

The TCA cycle is a universal feature of the metabolism in aerobic organisms. It begins with the condensation of OAA and acetyl-CoA proceeds via a series of oxidative steps that release two carbon atoms as $\mathrm{CO}_{2}$, and ends with the regeneration of OAA (Fig. 2). In plants, acetyl CoA is derived from the end product of glycolysis, pyruvate, by the action of mitochondrial pyruvate dehydrogenase. 
A Fe deficiency affects both aconitase and SDH

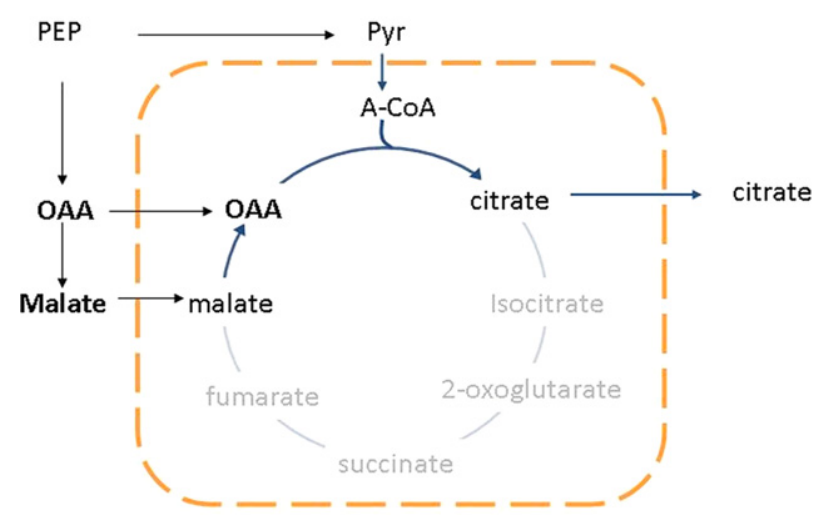

B Fe deficiency affects only SDH

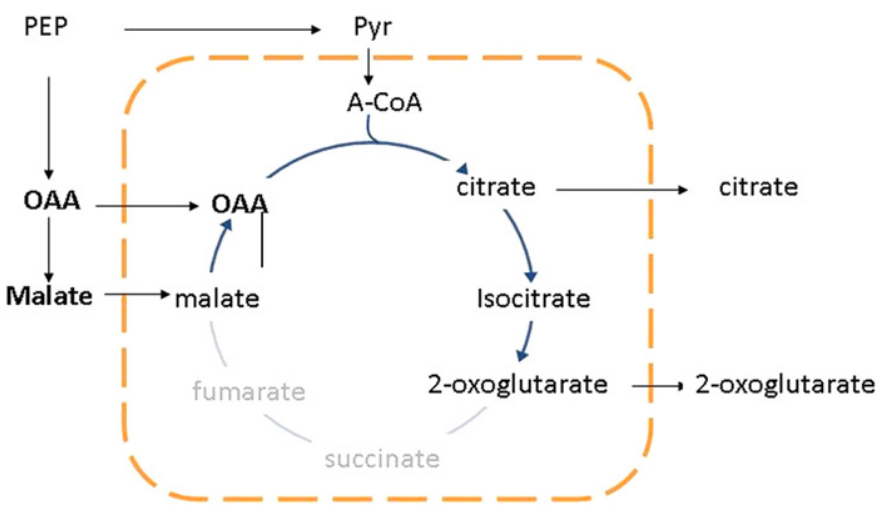

Fig. 2. Representation of the changes occurring at the TCA cycle level under Fe deficiency. (A) Hypothetical non-cyclic TCA mode occurring in the case of decrease of aconitase and SDH activities under Fe deficiency. (B) Hypothetical non-cyclic TCA mode occurring in the case of decrease of SDH activity under Fe deficiency.

The pyruvate is either imported directly from the cytosol or synthesised by the mitochondrial NAD-malic enzyme from malate that, in turn, is derived from cytosolic PEP. PEP carboxylase generates cytosolic OAA, which is readily converted to malate and aspartate. All three metabolites can be imported into the mitochondria to provide a source of malate for the NAD-malic enzyme (Sweetlove et al., 2010).

Several authors have suggested that Fe deficiency induces the activation of the TCA cycle. Li et al. (2008) observed that the expression of several TCA enzymes (isocitrate dehydrogenase, aconitase, succinyl-CoA ligase, and succinate dehydrogenase) was simultaneously upregulated in Fe-deficient tomato roots. López-Millán et al. (2009) showed that the total organic anion concentrations in tomato root tips did not change significantly with Fe deficiency, but their composition was markedly changed. In the control root tips, the major organic anions were oxalate, 2-OG and malate, whereas in Fe-deficient root tips, citrate and malate accounted for $90 \%$ of the total organic anion concentrations. Moreover, the authors showed that the activities of five enzymes (ICDH, aconitase, MDH, fumarase and $\mathrm{CS}$ ) involved in organic acid metabolism increased significantly in the tissue extracts of Fe-deficient root tips when compared with the Fe-sufficient tips. The authors pointed out that the upregulation of the TCA cycle might have special significance for roots responding to Fe deficiency. The TCA cycle provides abundant organic acids, including citrate and malate, which play an important role as chelators for Fe transport in plants (López-Millán et al., 2000b; Tiffin, 1966). A metabolite study in Beta vulgaris revealed large increases in organic acids related to the TCA cycle (Rellán-Álvarez et al., 2010).
Additionally, a proteomic analysis performed on Medicago truncatula roots revealed an increase in the amount of several TCA cycle enzymes under Fe-deficient conditions (Rodríguez-Celma et al., 2011). All these data suggest that the TCA cycle plays an important role in the Fe deficiency response by providing organic acids and protons for the acidification of the rhizosphere.

Nevertheless, none of the studies mentioned above involved the isolation of purified mitochondria. Therefore, they were unable to discriminate between the identical reactions occurring in the mitochondrial matrix and in the cytosol (i.e., reactions catalysed by aconitase, malate dehydrogenase and isocitrate dehydrogenase). One complication inherent in studying the TCA cycle is that almost all the steps in the pathway can be bypassed by steps in the cytosol; however, the reactions catalysed by citrate synthase and succinate dehydrogenase are exceptions.

Like the respiratory chain, the TCA cycle possesses two Fe-containing enzymes [i.e., aconitase and the succinate dehydrogenase (Complex II of the respiratory chain)]. As previously discussed, the succinate dehydrogenase activity in purified mitochondria obtained from cucumber roots (Vigani et al., 2009) and sycamore cells (Pascal and Douce, 1993) strongly decreased under Fe deficiency, suggesting that the TCA cycle was decelerated at least at some point.

Sweetlove et al. (2010) recently reviewed the different carboxylic acid metabolism flux modes predicted from metabolic models and concluded that cyclic TCA could not be just a cycle. They propose that the cyclic mode of TCA provides efficient energy transfer from the carbon bonds of respiratory substrates to ATP, suggesting that it might not be necessary to maintain the cyclic flux if the demand for ATP is low or if alternative sources of ATP are available. Consistent with this argument, a recent flux-balance model of heterotrophic Arabidopsis metabolism demonstrates that a cyclic TCA flux is only established as the demand for ATP increases in a cell (Poolman et al., 2009; Sweetlove et al., 2010).

It was proposed that the effect of Fe deficiency on the TCA cycle could induce different changes. Considering the expected decrease of aconitase and succinate dehydrogenase activities under Fe deficiency, the TCA cycle could shift from a circular to a linear mode, creating at least two metabolic scenarios (Fig. 2). First, if both aconitase and succinate dehydrogenase activities are strongly affected by Fe deficiency, the TCA cycle could similarly work as in the non-cyclic flux mode as predicted from the analysis of an enzyme kinetic model (Steuer et al., 2007); malate is imported into the matrix and then converted to citrate, which is subsequently exported from mitochondria (Fig. 2A). This hypothetical scenario is plausible because there is evidence for the accumulation of the di- and tricarboxylic acid carrier (DTC) protein under Fe deficiency, suggesting an increased transfer of organic acids, mainly malate and citrate, between the mitochondria and cytosol. Additionally, increased citrate export from the mitochondria to the cytosol has been observed in several species under Fe deficiency (Vigani and Zocchi, 2009 and references therein). However, there is no direct evidence that mitochondrial aconitase is affected by Fe deficiency, even if it would be expected.

Indeed, the second scenario implies that Fe deficiency affects only succinate dehydrogenase. In this case, the TCA cycle could work as in the non-cyclic flux mode predicted under conditions of low ATP demand in a genome-scale metabolic model of Arabidopsis (Poolman et al., 2009; Sweetlove et al., 2010); malate and/or OAA are imported into the matrix and then converted to 2-OG, which is subsequently exported from the mitochondrion together with citrate (Fig. 2B). This hypothesis is also reasonable because there is evidence for the strong inactivation of Complex II under Fe deficiency (Pascal and Douce, 1993; Vigani et al., 2009).

Taking into consideration that the TCA cycle does not necessarily support a cyclic flux and that the actual flux distribution 
through it will reflect the function of the whole metabolic network, a combination of these non-cyclic TCA modes could occur under Fe deficiency. Furthermore, the presence of a cyclic or non-cyclic mode of TCA might depend on the degree of stress. Indeed, it could be hypothesised that when the amount of Fe in the cell is close to zero, Fe-containing enzyme activities are inhibited, which leads to a non-cyclic TCA mode. When the amount of Fe is low but not depleted, the Fe-containing enzymes might still function, leading only to a slowing of the TCA cycle. In any case, the shift from a cyclic to a non-cyclic TCA mode under Fe deficiency could result from a necessity to maintain a functioning metabolism, even if important Fe-containing enzymes are not synthesised.

\section{Mitochondrial dynamics in Fe-deficient plants}

The morphology and ultrastructure of the mitochondria are also affected by Fe deficiency. In fact, mitochondria from Fedeficient sycamore cells displayed a more dilute matrix with less pronounced cristae (Pascal and Douce, 1993). Interestingly, in Fe-deficient cucumber roots, mitochondria displayed a particular handlebar-like structure and appeared to aggregate (Vigani et al., 2009) (Fig. 3A). However, the particular shape that was observed in Fe-deficient cucumber roots was also observed in the wild-type heterotrophic cells of Arabidopsis grown under control conditions, indicating that this shape is probably not specifically related to Fe deficiency (Tarantino et al., 2010b). A similar handlebar-like structure observed in Fe-deficient cucumber root has been observed in the Arabidopsis drp3a mutant (Logan, 2006, 2010) (Fig. 3). DRP3A is a dynamin-like protein that is required for the maintenance of mitochondrial size and number in Arabidopsis and rice; this protein has been partially localised to the poles of mitochondria and to sites of constriction (Arimura et al., 2004; Fujimoto et al., 2004; Logan et al., 2004). The disruption of DRP3A results in an aberrant mitochondrial morphology that is characterised by an increase in the size of individual mitochondria and a corresponding decrease in the number of mitochondria per cell (Logan, 2010 and references therein). Interestingly, drp3a mutants displayed mitochondria with the presence of a matrixule, a thin protuberance of up to many micrometers in length that extends from one pole of a mitochondrion (Fig. 3B). It has been proposed that the presence of numerous mitochondria with matrixules in $d r p 3 a$ mutants is linked to the function of DRP3A as a component of the mitochondrial division machinery (Logan, 2010 and references therein).

The higher plant chondriome (all the mitochondria in a cell, collectively) is a highly dynamic structure composed predominantly of physically discrete organelles. This structure contrasts with that of most animal cell types and yeast cells in which the chondriome is frequently organised into long tubules or reticula. An analysis of the mitochondrial morphology in vivo has shown that higher plant mitochondria are highly pleomorphic, although most frequently they are spherical to sausage-shaped organelles. Mitochondria are also dynamic in terms of their movement within cells, moving rapidly along cellular structures, such as actin and microtubule cytoskeletal elements (Logan, 2006, 2010 and references therein). The primary mitochondrial processes that regulate the shape and the movement of the organelles in the cell are fusion and fission. These two processes compensate for one another, leading to the maintenance of a relatively constant number of mitochondria in the cell (Logan, 2006, 2010). Several authors have reported that the number of mitochondria was increased in Fe-deficient cells (Landsberg, 1986, 1994; Pascal and Douce, 1993; Dell'Orto et al., 2002); therefore, it is rational to hypothesise that this nutritional stress could modify the mitochondrial fusion/fission ratio.

Because the plant chondriome is organised as a discontinuous whole, proper mitochondrial function requires fine control over the mitochondrial motility and cellular distribution. In fact, it is intrinsic in the discontinuous whole hypothesis that there is a 'need to meet', where the need is to provide a mechanism for the exchange of mitochondrial proteins; the fusion of physically discrete organelles requires mitochondrial movement (Logan, 2010). The control of mitochondrial positioning and direction of movement are the result of the coordinated activity of myosin and the rate of actin turnover (Logan, 2010).

Under Fe deficiency, the amount of actin decreases (Donnini et al., 2010), whereas the number of mitochondria increases. Mitochondrial motility has not been studied in Fe-deficient plants, and we do not known exactly how cells organise the cytoskeleton to allow organelle and vesicle trafficking in the cytosol. We might speculate that the increased number of mitochondria observed in Fe-deficient roots in several studies could be in response to an inefficient cytoskeletal structure to enhance the probability of mitochondrial contact, thus maintaining the discontinuous whole structure of the plant chondriome. In this way, the cell could satisfy the "need to meet" hypothesis. Interestingly, under Fe deficiency, mitochondrial contact results from a strongly affected metabolism in which the merging of mitochondria could help them to overcome the lack of Fe and at the same time, facilitate cell survival. Moreover, the probable shift towards a non-cyclic TCA mode increases mitochondrial communication with external components, within the cytosol and with other mitochondria. The fact that under a mild Fe deficiency, one of the first enzymes affected is Complex II (Pascal and Douce, 1993) would mean that mitochondria, perceiving an upcoming Fe deficiency, reprogram their own function, adjusting both the respiratory chain and the TCA cycle by acting on only one enzyme.

\section{Role of mitochondria in controlling the NADPH reduction levels under Fe deficiency}

The presence of type II NADPH dehydrogenases with different properties on both sides of the mitochondrial inner membrane allows the mETC to specifically regulate the reduction of either mitochondrial or cytosolic NADH or NADPH (Rasmusson and Wallström, 2010 and references therein). Importantly, metabolite exchangers, together with the activity of the TCA cycle enzymes, mediate reductant shuttling across the inner mitochondrial membrane, modulating the turnover of reducing equivalents in both the mitochondria and the cytosol. Indeed, the reduction of NADH in the matrix and the cytosol are believed to equilibrate primarily with the malate/OAA ratios in each compartment, while the reduction of NADPH pools between the matrix and cytosol is equilibrated through the export of reductant from mitochondrion to the cytosol by both a citrate valve that exchanges citrate and 2oxoglutarate (Igamberdiev and Gardeström, 2003) and a malate valve that exchanges malate and OAA (Scheibe, 2004).

In this context, the reducing power turnover of Fe-deficient cells undergoes a fine and complex regulation to satisfy the metabolic request. Indeed, because both the cytosolic NADPH and the mitochondrial NADPH need to be re-oxidised to keep the catabolic pathways working, a less active respiratory chain could impair this turnover, leading to a higher reduced/oxidised NADP ratio, as shown by the increased NADPH/NADP ${ }^{+}$ratio in Fe-deficient bean and Plantago lanceolate (Sijmons et al., 1984; Schmidt and Schuck, 1996). However, in Fe-deficient sugar beet and tomato roots, the $\mathrm{NADPH} / \mathrm{NADP}^{+}$ratio was lower than the relative control conditions (López-Millán et al., 2000a,b, 2009), suggesting that Fe deficiency might stimulate the NADPH-oxidising activities more that the $\mathrm{NADP}^{+}$-reducing activities.

To oxidise the large production of NADPH from metabolism, the cell activates reactions that are able to consume NADPH. 


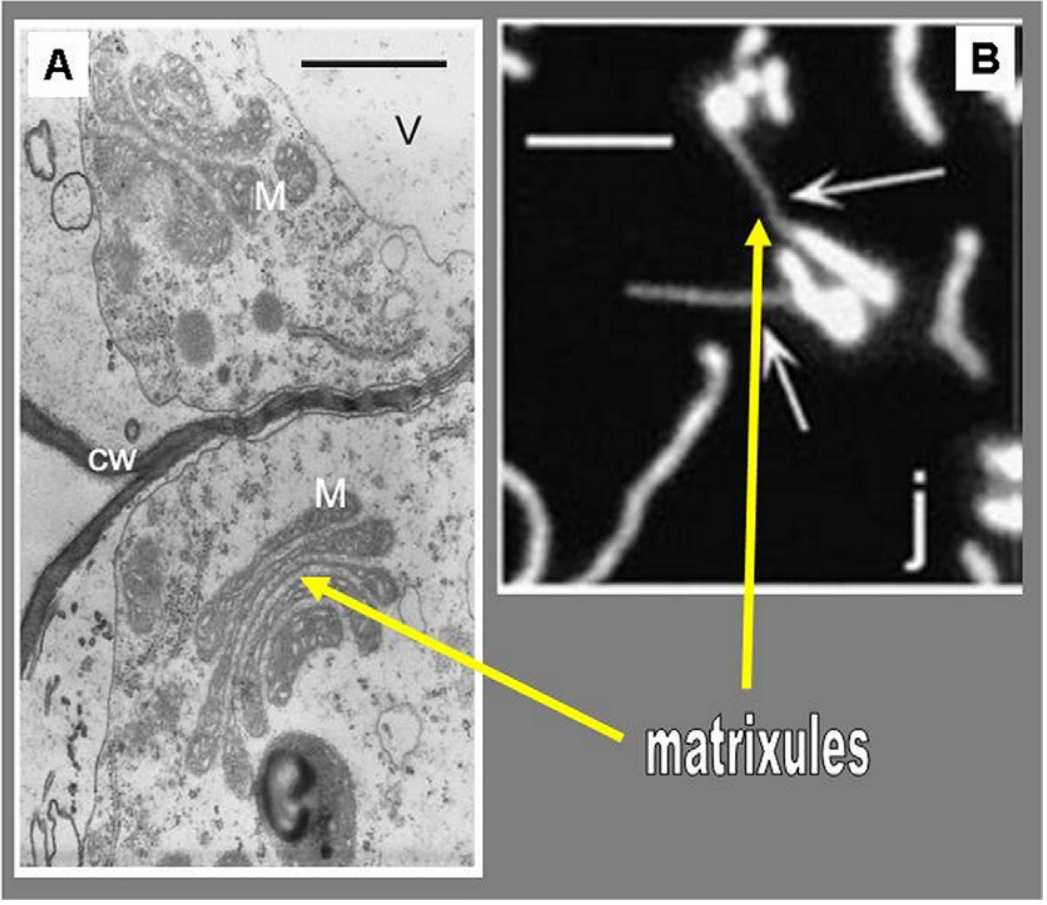

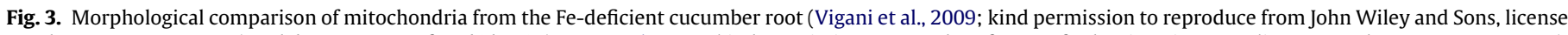

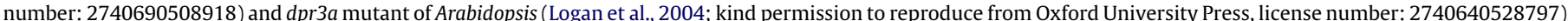

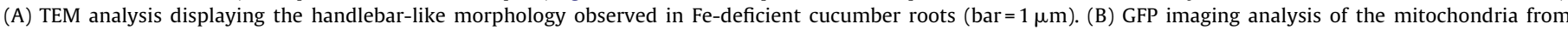

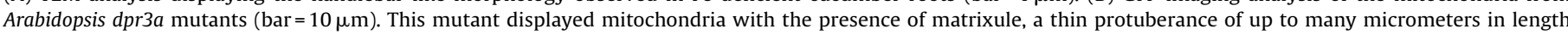

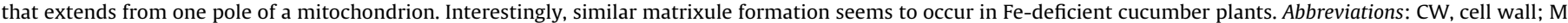
mitochondrion; $\mathrm{V}$, vacuole.

López-Millán et al. (2000a,b, 2009) reported that Fe deficiency increased the activities of fermentative enzymes, such as lactate dehydrogenase (LDH), pyruvate decarboxylase (PDC) and several other cytosolic NADH-consuming enzymes, which could contribute to the oxidation of the pyridine nucleotide pool in tomato and sugar beet roots. These data were also confirmed by microarray analysis of Fe-deficient Arabidopsis (Thimm et al., 2001) and proteomic data obtained from cucumber roots, in which putative alcohol dehydrogenase and malate dehydrogenase proteins accumulated under Fe deficiency (Donnini et al., 2010). The mitochondria might participate in the oxidation of NADPH under Fe deficiency by the activation of their alternative pathways (i.e., NADPH DHs). The external and internal localisation of these enzymes in the inner mitochondrial membrane allows them to oxidise the NADPH on both the cytosol and the matrix sides (Vigani and Zocchi, 2010).

Because Fe deficiency leads to a strong energy demand in the cell, the activation of mitochondrial metabolism would represent the perfect solution for the cell. However, the lack of Fe strongly affects mitochondrial functionality. Nevertheless, the activity of the plant mitochondria results in a complicated reprogramming of their own metabolism. At the level of the respiratory chain, alternative pathways are induced, bypassing the impaired complexes. The TCA pathway could shift from a cyclic to a non-cyclic mode, bypassing the limiting step (for instance, succinate dehydrogenase) and improving external communication. This bypass might be accomplished by inducing both the anaplerotic reactions to produce organic acids (which are useful for the responses to Fe deficiency) and the metabolite shuttles to allow the recycling of reducing power. The cell, in some way, helps mitochondria satisfy their "need to meet", which would be high under Fe deficiency, by increasing the number of mitochondria. To facilitate mitochondrial activity, the cell could obtain useful compounds for rhizosphere acidification and Fe chelation, such as organic acid and flavins, which result from the disuse of Complexes I and II (Fig. 4).
Overall, the metabolic alteration of Fe-deficient root cells depends on the mitochondrial functionality. This organelle, which represents the "Iron-Area" of a root cell, seems to be the main target of the Fe deficiency, which might also become a starting point for whole cellular metabolic reprogramming to overcome this emergency energetic status (Vigani and Zocchi, 2010). The Fe deficiency establishes a cellular effort in which mitochondria activate alternative pathways to sustain NADPH turnover and organic acid synthesis. In this way, mitochondria facilitate the increase of glycolysis, which becomes a strong source of energy substrates for the activation of the response to Fe deficiency.

\section{Could mitochondria be involved in the signal transduction of the Fe-deficient status of the cell?}

The mitochondrion occupies an integrated position in the metabolic network of plants, reflecting the evolutionary origins of the organelle. Indeed, through its integration into the ancestral eukaryotic cell, the mitochondrion provided a new arsenal of metabolic capabilities (Martin and Russell, 2003; Sweetlove et al., 2007). To communicate with external compartments, mitochondria generate several compounds as signals, such as ROS and organic acid. It is well known that mitochondria produce ROS that not only cause damage to cellular components but are also involved in intracellular signalling; $\mathrm{H}_{2} \mathrm{O}_{2}$ is considered the most likely messenger (Neil et al., 2002; Møller et al., 2011). Importantly, abiotic stress influences mitochondrial $\mathrm{H}_{2} \mathrm{O}_{2}$ production (Møller, 2001), which could generate secondary signals and therefore transduce the oxidative damage of the mitochondrial component to the cell (Halliwell, 2006; Rhoads et al., 2006). Indeed, because $\mathrm{H}_{2} \mathrm{O}_{2}$ does not have the required specificity to regulate specific genes, it has been proposed that (carbonylated) peptides deriving from the proteolytic degradation of oxidised protein could irreversibly be the specific secondary ROS messenger from 

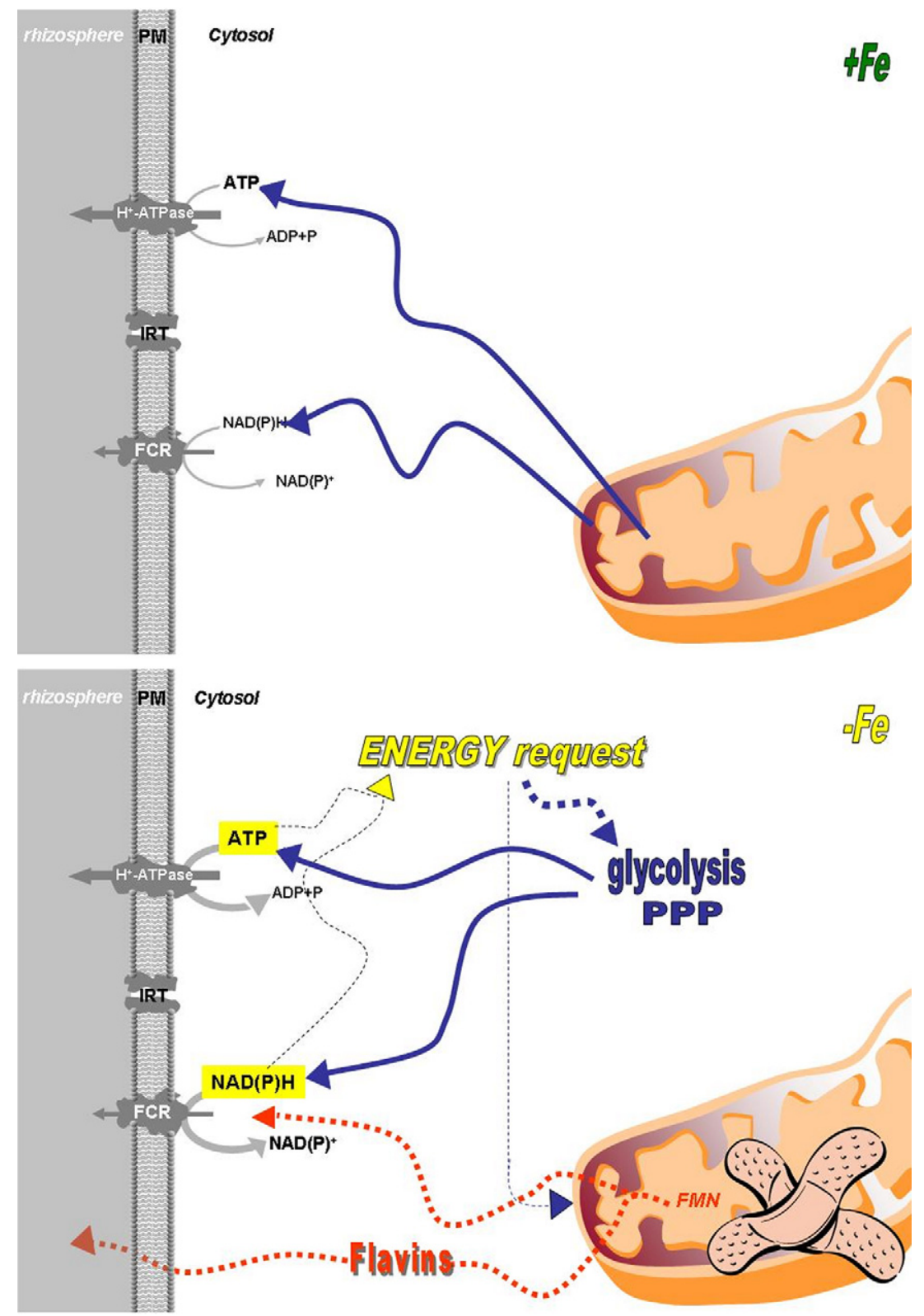

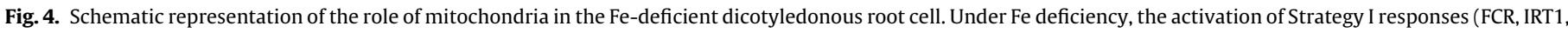

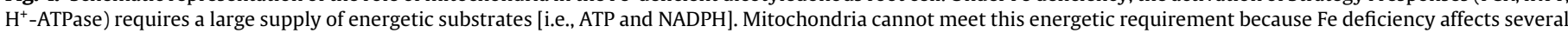

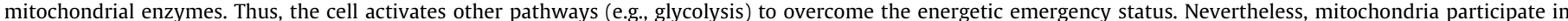

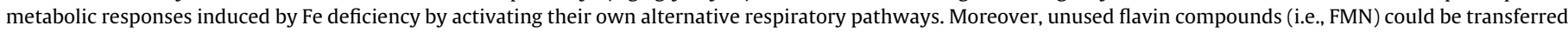
to the cytosol and extruded into the rhizosphere, facilitating the Fe reduction activity.

mitochondria to regulated source-specific genes (Møller and Sweetlove, 2010; Møller et al., 2011). The relationships between Fe deficiency and secondary oxidative stress remain controversial because iron is either a constituent or a cofactor of many antioxidant enzymes and simultaneously acts as a prooxidant through the Fenton reaction (Halliwell, 2006). However, Fe deficiency is associated with an accumulation of ROS (Donnini et al., 2011). In addition to ROS, it has been suggested that TCA-cycle intermediates might be potent regulators of gene expression in a manner analogous to sugars (Finkemeier and Sweetlove, 2006; Sweetlove et al., 2007). Indeed, the intermediates of the TCA cycle could communicate the mitochondrial metabolic status to the cytosol by virtue of the presence of di- and tri-carboxylic acid transporter (DTC) proteins located in the inner mitochondrial membrane (Picault et al., 2002). The exogenous application of citrate, malate and 2-oxoglutarate could induce AOX expression (Gray et al., 2004), suggesting that it is the extra-mitochondrial levels of the TCA cycle metabolites that are sensed. Under Fe deficiency, a number of organic acids, such as citrate, are synthesised in the root cells from the TCA cycle. Moreover, DTC proteins accumulate in Fe-deficient cucumber roots (Vigani et al., 2009). The multiple roles for citrate are: Fe chelation, Fe transport, the regulation of cellular $\mathrm{pH}$, and as a carbon skeleton source. Because of its multiple functions, citrate exported from the mitochondrion might be both in response to the Fe deficiency and an indicator of the metabolic status of the cell, together with the induction of several mitochondrial metabolic carriers that are able to strongly activate the exchange of organic acids and reducing equivalent compounds with the cytosol. Indeed, the cytosolic reducing equivalents might be transferred to the mitochondria through both specific reducing equivalent shuttles, such as glycerol-3-phosphate (G-3-P) shuttle (Shen et al., 2003, 2006) and several metabolite shuttles that operate between the two 
compartments, including shuttles for malate/OAA (Ebbighausen et al., 1985) and malate/aspartate (Journet et al., 1981).

There is accumulating evidence for calcium $\left(\mathrm{Ca}^{2+}\right)$ involvement in mitochondrial signalling. In fact, $\mathrm{Ca}^{2+}$ itself might be an important part of the signal transduction pathways that originate from the mitochondria. Mitochondria contain relatively high concentrations of $\mathrm{Ca}^{2+}$ (Logan and Knight, 2003) and can be considered intracellular $\mathrm{Ca}^{2+}$ stores. Moreover, mitochondrial $\mathrm{Ca}^{2+}$ might be released into the cytosol during abiotic stress (Subbaiah et al., 1994), and there is evidence that mitochondrial $\mathrm{Ca}^{2+}$ levels respond to environmental signals (Logan and Knight, 2003). However, there is no clear evidence for $\mathrm{Ca}^{2+}$ involvement in the transduction of Fe deficiency-inducible responses. However, indirect findings suggest that $\mathrm{Ca}^{2+}$ might act as a second messenger in targeting the Fe deficiency signal in roots. In fact, Buckhout et al. (2009) reported the induction of genes encoding 14-3-3 proteins and some protein kinases in Fe-deficient Arabidopsis roots, which would be target proteins of the $\mathrm{Ca}^{2+}$-calmodulin-transduced signal. Moreover, in Fe-deficient cucumber roots, it has been observed that a gene encoding calmodulin was overexpressed and its relative protein level was increased (Vigani et al., in press). Overall, these data suggest that $\mathrm{Ca}^{2+}$ is potentially involved in the transduction of $\mathrm{Fe}$ deficiency signals and that the mitochondria could participate in targeting the signal of altered Fe nutritional status.

Another well-known second messenger that could also be important in mitochondrial signal transduction is nitric oxide (NO). It is well documented that plants generate NO and that NO can act as an important signal molecule in a variety of scenarios (Wendehenne et al., 2004; Shapiro, 2005).

In plants, there are reports suggesting the existence of NO synthase (NOS)-like activities in various developmentally and physiologically stressful situations (Corpas et al., 2009). However, the existence of NOS in plant mitochondria is doubtful (Gupta et al., 2010). Indeed, it has been recently shown that plant mitochondria might be involved in NO turnover by the inter-conversion of nitrite and NO at the site of complex IV. Cytochrome $c$ oxidase could represent the most plausible and established candidate for the nitrite-to-NO conversion, although other components of mETC could perform this reaction (Gupta and Igamberdiev, 2011 and references therein).

Importantly, NO has also recently been demonstrated to be involved in the induction of Fe-deficiency responses. Indeed, it has been shown that the NO level in roots was rapidly and continually elevated when plants were transferred to an Fe-deficient growth medium (Graziano and Lamattina, 2007; Jin et al., 2009; Chen et al., 2010). Furthermore, it has been observed that NO is required for the molecular events involved in controlling the development of lateral (Correa-Aragunde et al., 2004; Mendez-Bravo et al., 2010) and cluster roots (Wang et al., 2010), which are typical morphological changes that occur under Fe deficiency in several plants (Landsberg, 1994; Dell'Orto et al., 2002).

Thus, it is clear that mitochondria have several signal types that might be involved in Fe deficiency signal transduction.

\section{Concluding remarks}

As in other organisms, changes in the availability of Fe in plant mitochondria determine the reorganisation of cellular metabolism. The complex alteration of root metabolism under Fe deficiency has been reviewed here, discussing old and new findings. It is clear that mitochondria represent a central site of the metabolic regulation in the cell. In the case of low Fe availability, plant mitochondria become both a victim and a crucial site of fascinating alternative processes that make them unique in their role. The mitochondrion is probably the most affected compartment of the root cell under Fe deficiency. Nevertheless, it is not destined just to succumb but to play a central role, through the effective modulation of the respiratory chain and the TCA cycle, in the Fe-deficient metabolic network. The mitochondrial flexibility in the development of the adaptive response to Fe deficiency is not only related to metabolism but also in mitochondrial dynamics. Moreover, the importance of mitochondria as possible signal-producing sites suggests an intriguing hypothesis that the mitochondrion might act as a cellular-stress sensor of Fe deficiency for the induction of the metabolic reprogramming of the cell.

Therefore, it would be of interest to concentrate future research on understanding how Fe deficiency influences mitochondria and vice versa, that is, how mitochondrial remodelling facilitates the reprogramming of root cell metabolism.

\section{Acknowledgments}

I wish to thank Prof. Graziano Zocchi and Dr. Marta Dell'Orto for critically reading the manuscript. I also wish to thank the anonymous reviewers for their precious comments to improve the manuscript.

\section{References}

Abadía J, López-Millán AF, Rombolà A, Abadía A. Organic acids and Fe deficiency: a review. Plant Soil 2002;241:75-86.

Abadía J, Vázquez S, Rellán-Álvarez R, El-Jendoubi H, Abadía A, Álvarez-Fernández A, et al. Towards a knowledge-based correction of iron chlorosis. Plant Physiol Biochem 2011., doi:10.1016/j.plaphy.2011.01.026.

Aisen P, Enns C, Wessling-Resnick M. Chemistry and biology of eukaryotic iron metabolism. Int J Biochem Cell Biol 2001;33:940-59.

Andaluz S, Rodríguez-Celma J, Abadía A, Abadía J, López-Millán AF. Time course induction of several key enzymes in Medicago truncatula roots in response to $\mathrm{Fe}$ deficiency. Plant Physiol Biochem 2009;47:1082-8.

Andrews NC. Forging a field: the golden age of iron biology. Blood 2008;112:219-30.

Arimura S, Aida GP, Fujimoto M, Nakazono M, Tsutsumi N. Arabidopsis dynamin-like protein $2 \mathrm{a}$ (ADL2a), like ADL2b, is involved in plant mitochondrial division. Plant Cell Physiol 2004;45:236-42.

Arosio P, Ingrassi R, Cavadini P. Ferritins: a family of molecules for iron storage, antioxidation and more. Biochim Biophys Acta 2009;1790:589-99.

Balk J, Lobréaux S. Biogenesis of iron-sulfur proteins in plants. Trends Plant Sci 2005;10:324-31.

Balk J, Pilon M. Ancient and essential: the assembly of iron-sulfur clusters in plants. Trends Plant Sci 2011;16:218-26.

Bashir K, Ishimaru Y, Shimo H, Nagasaka S, Fujimoto M, Takanashi H, et al. The rice mitochondrial iron transporter is essential for plant growth. Nat Commun 2011;2:322.

Bertini I, Rosato A. From genes to metalloproteins: a bioinformatic approach. WileyVCH Verlag; 2007. p. 2546-2555.

Briat JF, Duc C, Ravet K, Gaymard F. Ferritins and iron storage in plants. Biochim Biophys Acta 2010a;1800:806-14.

Briat JF, Ravet K, Arnaud N, Duc C, Boucherez J, Touraine B, et al. New insights into ferritin synthesis and function highlight a link between iron homeostasis and oxidative stress in plants. Ann Bot 2010b;105:811-22.

Buckhout TJ, Yang TJ, Schmidt W. Early iron-deficiency-induced transcriptional changes in Arabidopsis roots as revealed by microarray analyses. BMC Genomics 2009;10:147.

Cesco S, Neumann G, Tomasi N, Pinton R, Weisskopf L. Release of plant borne flavonoids into the rhizosphere and their role in plant nutrition. Plant Soil 2010;329:1-25.

Chen WW, Yang JL, Qin C, Jin CW, Mo JH, Ye T, et al. Nitric oxide acts downstream of auxin to trigger root ferricchelate reductase activity in response to iron deficiency in Arabidopsis. Plant Physiol 2010;154:810-9.

Conte SS, Walker EL. Transporters contributing to iron trafficking in plants. Mol Plant 2011;4:464-76.

Corpas FJ, Palma JM, Del Rio LA, Barroso JB. Evidence supporting the existence of L-arginine-dependent nitric oxide synthase activity in plants. New Phytol 2009;184:9-14.

Correa-Aragunde N, Graziano M, Lamattina L. Nitric oxide plays a central role in determining lateral root development in tomato. Planta 2004;218:900-5.

Curie C, Briat JF. Iron transport and signalling in plants. Annu Rev Plant Biol 2003;54:183-206

Curie C, Panaviene Z, Loulergue C, Dellaporta SL, Briat JF, Walker EL. Maize yellow stripe 1 encodes a membrane protein directly involved in $\mathrm{Fe}(\mathrm{III})$ uptake. Nature 2001:409:346-9.

De Domenico I, McVey Ward D, Kaplan J. Regulation of iron acquisition and storage: consequences for iron-linked disorders. Nat Rev Mol Cell Biol 2008;9: $72-81$. 
De Nisi P, Vigani G, Zocchi G. Modulation of iron responsive gene expression and enzymatic activities in response to changes of the iron nutritional status in Cucumis sativus L.; 2010, Available from Nature Precedings. http://dx.doi.org/10.1038/npre.2010.4658.1.

De Nisi P, Zocchi G. Phoephoenolpyruvate carboxylase in cucumber (Cucumis sativus L.) roots under iron deficiency: activity and kinetic characterization. J Exp Bot 2000;51:1903-9.

Dell'Orto M, Pirovano L, Villalba JM, Gonzalez-Reyes JA, Zocchi G. Localization of the plasma membrane $\mathrm{H}^{+}$-ATPase in Fe-deficient cucumber roots by immunodetection. Plant Soil 2002;241:11-7.

Dell'Orto M, Santi S, De Nisi P, Cesco S, Varanini Z, Zocchi G, et al. Development of Fe deficiency responses in cucumber (Cucumis sativus L.) roots: involvement of plasma membrane $\mathrm{H}^{+}$-ATPase activity. J Exp Bot 2000;51:695-701.

Donnini S, Prinsi B, Negri AS, Vigani G, Espen L, Zocchi G. Proteomic characterization of iron deficiency responses in Cucumis sativus L. roots. BMC Plant Biol 2010;10:268.

Donnini S, Dell'Orto M, Zocchi G. Oxidative stress responses and root lignifications induced by Fe deficiency condition in pear and quince genotype. Tree Physiol 2011;31:102-13.

Douce R, Neuberger M. The uniqueness of plant mitochondria. Annu Rev Plant Physiol Plant Mol Biol 1989;40:371-414.

Douce R. Function of plant mitochondrial membranes; mitochondria in higher plants. American Society of Plant Physiologists Monograph Series. London: Academic Press; 1985. p. 77-153.

Ebbighausen H, Chen J, Heldt HW. Oxaloacetate translocator in plant mitochondria. Biochim Biophys Acta 1985;810:184-99.

Eckhardt U, Mas Marques A, Buckhout TJ. Two iron-regulated cation transporters from tomato complement metal uptake-deficient yeast mutants. Plant Mol Biol 2001;45:437-48.

Eide DJ, Broderius M, Fett J, Guerinot ML. A novel iron-regulated metal transporter from plants identified by functional expression in yeast. Proc Natl Acad Sci USA 1996;93:5624-8.

Eisenstein RS. Iron regulatory proteins and the molecular control of mammalian iron metabolism. Annu Rev Nutr 2000;20:627-62.

Espen L, Dell'Orto M, De Nisi P, Zocchi G. Metabolic responses in cucumber (Cucumis sativus L.) roots under Fe-deficiency: a 31P-nuclear magnetic resonance in vivo study. Planta 2000;210:985-92.

Finkemeier I, Sweetlove LJ. Signalling in primary metabolism. New Phytol 2006;171:445-7.

Fujimoto M, Arimura S, Nakazono M, Tsutsumi N. A rice dynamin-like protein, OsDRP3A, is involved in mitochondrial fission. Breed Sci 2004;54:367-72.

Galaris D, Pantopoulos K. Oxidative stress and iron homeostasis: mechanistic and health aspects. Crit Rev Clin Lab Sci 2008;45:1-23.

Gonzalez-Vallejo EB, Susín S, Abadía A, Abadía J. Changes in sugar beet leaf plasma membrane Fe(III)-chelate reductase activities mediated by Fe deficiency, assay buffer composition, anaerobiosis and the presence of flavins. Protoplasma 1998;205:163-8.

Gray GR, Maxwell DP, Villarimo AR, McInotosh L. Mitochondria/nuclear signalling of alternative oxidase gene expression occurs through distinct pathways involving organic acids and reactive oxygen species. Plant Cell Rep 2004;23: 497-503.

Graziano M, Lamattina L. Nitric oxide accumulation is required for molecular and physiological responses to iron deficiency in tomato roots. Plant J 2007;52:949-60.

Gupta KJ, Igamberdiev AU, Kaiser WM. New insights into the mitochondrial nitric oxide production pathways. Plant Signal Behav 2010;5:999-1001.

Gupta KJ, Igamberdiev AU. The anoxic plant mitochondrion as a nitrite: NO reductase. Mitochondrion 2011;11:537-43.

Halliwell B. Reactive species and antioxidants. Redox biology is a fundamental theme of aerobic life. Plant Physiol 2006;141:312-22.

Hentze MW, Muckenthaler MU, Galy B, Camaschella C. Two to tango: regulation of mammalian iron metabolism. Cell 2010;142:24-38.

Higa A, Mori Y, Kitamura Y. Iron deficiency induces changes in riboflavin secretion and the mitochondrial electron transport chain in hairy roots of Hyoscyamus albus. J Plant Physiol 2010;167:870-8.

$\mathrm{Hu}$ J, Dong L, Outten CE. The redox environment in the mitochondrial intermembrane space is maintained separately from the cytosol and matrix. J Biol Chem 2008;283:29126-34.

Igamberdiev AU, Gardeström P. Regulation of NAD- and NADP-dependent isocitrate dehydrogenases by reduction levels of pyridine nucleotides in mitochondria and cytosol of pea leaves. Biochim Biophys Acta 2003;1606:117-25.

Jelali N, M'sehli W, Dell'Orto M, Abdelly C, Gharsalli M, Zocchi G. Changes of metabolic responses to direct and induced Fe deficiency of two Pisum sativum cultivars. Environ Exp Bot 2010;68:238-46.

Jin CW, Du ST, Chen WW, Li GX, Zhang YS, Zheng SJ. Elevated carbon dioxide improves plant Fe nutrition through enhancing the Fe-deficiencyinduced responses under Fe-limited conditions in tomato. Plant Physiol 2009;150:272-80.

Journet EP, Neuburger M, Douce R. The role of glutamate oxaloacetate transaminase and malate dehydrogenase in the regeneration of $\mathrm{NAD}^{+}$for glycine oxidation by spinach leaf mitochondria. Plant Physiol 1981;67:467-9.

Kannan S. Physiological-responses associated with Fe-deficiency stress in different plant species. J Plant Nutr 1988;11:1185-92.

Kell DB. Iron behaving badly: inappropriate iron chelation as a major contributor to the aetiology of vascular and other progressive inflammatory and degenerative diseases. BMC Med Genomics 2009;2:2.
Koppenol WH. The centennial of the Fenton reaction. Free Radic Biol Med 1993; 15:645-51.

Kushnir S, Babiychuk E, Storozhenko S, Davey M, Papenbrock J, De Rycke R, et al. A mutation of the mitochondrial $\mathrm{ABC}$ transporter Sta1 leads to dwarfism and chlorosis in the Arabidopsis mutant starik. Plant Cell 2001;13:89-100.

Lan P, Li W, Wen TN, Shiau JY, Wu YC, Lin W, et al. iTRAQ protein profile analysis of Arabidopsis roots reveals new aspects critical for iron homeostasis. Plant Physiol 2011;155:821-34.

Landsberg EC. Function of rhizodermal transfer cells in the Fe stress response mechanism of Capsicum annuum L. Plant Physiol 1986;82:511-7.

Landsberg EC. Transfer cell formation in sugar beet roots induced by latent Fe deficiency. Plant Soil 1994;165:197-205.

Li J, Wu X, Hao S, Wang X, Ling H. Proteomic response to iron deficiency in tomato root. Proteomics 2008;8:2299-311.

Logan DC. The mitochondrial compartment. J Exp Bot 2006;57:1225-43.

Logan DC. Mitochondrial fusion, division and positioning in plants. Biochem Soc Trans 2010;38:789-95.

Logan DC, Knight MR. Mitochondrial and cytosolic calcium dynamics are differentially regulated in plants. Plant Physiol 2003;133:21-4.

Logan DC, Scott I, Tobin AK. ADL2a, like ADL2b, is involved in the control of higher plant mitochondrial morphology. J Exp Bot 2004;55:783-5.

López-Millán AF, Morales F, Andaluz S, Gogorcena Y, Abadía A, De Las Rivas J, et al Responses of sugar beet roots to iron deficiency. Changes in carbon assimilation and oxygen use. Plant Physiol 2000a;124:885-98.

López-Millán AF, Morales F, Abadia A, Abadia J. Effects of iron deficiency on the composition of the leaf apoplastic fluid and xylem sap in sugar beet. Implications for iron and carbon transport. Plant Physiol 2000b;124:873-84.

López-Millán AF, Morales F, Gogorcena Y, Abadia A, Abadia J. Metabolic responses in iron deficient tomato plants. J Plant Physiol 2009;166:375-84.

M'Sehli W, Dell'Orto M, Donnini S, De Nisi P, Zocchi G, Abdelly C, et al. Variability of metabolic responses and antioxidant defence in two lines of Medicago ciliaris to Fe deficiency. Plant Soil 2008;320:219-30.

Mackenzie S, McIntosh L. Higher plant mitochondria. Plant Cell 1999;11:571-86.

Malinardi MV, Busi MV, Turowski VR, Leaden L, Araya A, Gomez-Casati DF. The mitochondrial protein frataxin is essential for heme biosynthesis in plants. FEBS 2011;278:470-81.

Martin W, Russell MJ. On the origin of the cells: a hypothesis for the evolutionary transitions from abiotic geochemistry to chemoautotrophic prokaryotes and from prokaryotes to nucleated cells. Philos Trans R Soc Land Ser B Biol Sci 2003;358:59-83.

Mendez-Bravo A, Raya-Gonzalez J, Herrera-Estrella L, Lopez-Bucio L. Nitric oxide is involved in alkamide-induced lateral root development in Arabidopsis. Plant Cell Physiol 2010;51:1612-26.

Millar AH, Whelan J, Soole KL, Day DA. Organization and regulation of mitochondria respiration in plants. Annu Rev Plant Biol 2011;62:79-104.

Møller IM, Rogowska-Wrzesinska A, Rao RSP. Protein carbonylation and metal-catalyzed protein oxidation in a cellular perspective. J Prot 2011. doi:10.1016/j.jprot.2011.05.004.

Møller IM, Sweetlove LJ. ROS signalling-specificity is required. Trends Plant Sci 2010;15:370-4.

Møller IM. Plant mitochondria and oxidative stress: electron transport, NADPH turnover, and metabolism of reactive oxygen species. Annu Rev Plant Physio Plant Mol Biol 2001;52:561-91.

Mukherjee I, Campbell N, Ash J, Connolly E. Expression profiling of the Arabidopsis ferric chelate reductase (FRO) gene family reveals differential regulation by iron and copper. Planta 2006;223:1178-90.

Nagarajah S, Ulrich A. Iron nutrition of the sugar beet plant in relation to growth, mineral balance, and riboflavin formation. Soil Sci 1966;102:399-407.

Neil S, Desikan R, Hancock J. Hydrogen peroxide signalling. Curr Opin Plant Biol 2002;5:388.

Nouet C, Motte P, Hanikenne M. Chloroplastic and mitochondrial metal homeostasis Trend Plant Sci 2011;16:395-404

Pascal N, Douce R. Effect of iron deficiency on the respiration of sycamore (Acer pseudoplatanus L.) calls. Plant Physiol 1993;103:1329-38.

Picault N, Palmieri L, Pisano L, Hodges M, Palmieri F. Identification of a novel transporter for dicarboxylates and tricarboxylates in plant mitochondria. Bacterial expression, reconstitution, functional characterization, and tissue distribution. J Biol Chem 2002;277:24204-11.

Poolman MG, Miguet L, Sweetlove LJ, Fell DA. A genome-scale metabolic model of Arabidopsis and some of its properties. Plant Physiol 2009;151:1570-81.

Pound GS, Welkie GW. Iron nutrition of Nicotiana tabacum L. in relation to multiplication of tobacco mosaic virus. Virology 1958;5:371-81.

Rabotti G, De Nisi P, Zocchi G. Metabolic implications in the biochemical responses to iron deficiency in cucumber (Cucumis sativus L.) roots. Plant Physio 1995;107:1195-9.

Rabotti G, Zocchi G. Plasma membrane-bound H+-ATPase and reductase activities in Fe-deficient cucumber roots. Physiol Plant 1994:90:779-85.

Rasmusson AG, Wallström SV. Involvement of mitochondria in the control of plant cell NAD(P)H reduction levels. Biochem Soc Trans 2010;38:661-6.

Rellán-Álvarez R, Andaluz S, Rodríguez-Celma J, Wohlgrmuth G, Zocchi G, ÁlvarezFernández A, et al. Changes in the proteomic and metabolic profiles of Beta vulgaris root tips in response to iron deficiency and resupply. BMC Plant Biol 2010;10:120-34.

Rhoads DM, Umbach AL, Subbaiah CC, Siedow JN. Mitochondrial reactive oxygen species. Contribution to oxidative stress and interorganellar signalling. Plant Physiol 2006;141:357-66. 
Robinson NJ, Procter CM, Connolly EL, Guerinot ML. A ferric-chelate reductase for iron uptake from soils. Nature 1999;397:694-7.

Rodríguez-Celma J, Lattanzio G, Grusak MA, Abadía A, Abadía J, López-Millán AF. Root responses of Medicago truncatula plants grown in two different iron deficiency conditions: changes in root protein profile and riboflavin biosynthesis. J Proteome Res 2011;10:2590-601.

Santi S, Cesco S, Varanini Z, Pinton R. Two plasma membrane $\mathrm{H}^{+}$-ATPase genes are differentially expressed in iron-deficient cucumber plants. Plant Physio Biochem 2005;43:287e292.

Santi S, Schmidt W. Dissecting iron deficiency-induced proton extrusion in Arabidopsis roots. New Phytol 2009;183:1072-84.

Santi S, Schmidt W. Laser microdissection-assisted analysis of the functional fate of iron deficiency-induced root hairs in cucumber. J Exp Bot 2008;59:697-704.

Schagerlof U, Wilson G, Hebert H, Al-Karadaghi S, Hagerhall C. Transmembrane topology of FRO2, a ferric chelate reductase from Arabidopsis thaliana. Plant Mol Biol 2006;62:215-21

Scheibe R. Malate valves to balance cellular energy supply. Physiol Plant 2004;120:21-6.

Schmidt W, Schuck C. Pyridine nucleotide pool size changes in iron-deficient Plantago lanceolata roots during reduction of external oxidants. Physiol Plant 1996:98:215-21.

Schmidt W. Mechanism and regulation of reduction-based iron uptake in plants. New Phytol 1999;141:1-26.

Shapiro AD. Nitric oxide signaling in plants. Vitam Horm 2005;72:339-98.

Shen W, Wei Y, Dauk M, Tan Y, Taylor DC, Selvaraj G, et al. Involvement of a glycerol-3-phosphate dehydrogenase in modulating the NADH/NAD1 ratio provides evidence of a mitochondrial glycerol-3-phosphate shuttle in Arabidopsis. Plant Cell 2006;18:422-41.

Shen W, Wei Y, Dauk M, Zheng Z, Zou J. Identification of a mitochondrial glycerol-3 phosphate dehydrogenase from Arabidopsis thaliana: evidence for a mitochondrial glycerol-3 phosphate shuttle in plants. FEBS Lett 2003;536:92-6.

Sijmons PC, Bienfait HF. Source of electrons for extracellular Fe(III) reduction in iron-deficient bean plants. Physiol Plant 1983;59:409-15.

Sijmons PC, Van Den Briel W, Bienfait HF. Cytosolic NADPH is the electron donor for extracellular FeIII reduction in iron-deficient bean roots. Plant Physio 1984;75:219-21.

Slatni T, Vigani G, Ben SI, Kouas S, Dell'Orto M, Gouia H, et al. Metabolic changes of iron uptake in $\mathrm{N}_{2}$-fixing common bean nodules during iron deficiency. Plant Sci 2011;181:151-8.

Steuer R, Nunes Nesi A, Fernie AR, Gross T, Blasius B, Selbig J. From structure to dynamics of metabolic pathways: application to the plant mitochondrial TCA cycle. Bioinformatics 2007;23:1378-85.

Subbaiah CC, Bush DS, Sachs MM. Elevation of cytosolic calcium precedes anoxic gene expression in maize suspension-cultured cells. Plant Cell 1994;6:1747-62.

Sweetlove LJ, Beard KFM, Nunes-Nesi A, Fernie AR, Ratcliffe RG. Not just a circle: flux modes in the plant TCA cycle. Trends Plant Sci 2010;15:462-70.

Sweetlove LJ, Fait A, Nunes-Nesi A, Williams T, Fernie AR. The mitochondrion: an integration point of cellular metabolism and signalling. Crit Rev Plant Sci 2007;26:17-43.

Tan YF, O’Toole N, Taylor NL, Millar AH. Divalent metal ions in plant mitochondria and their role in interactions with proteins and oxidative stress-induced damage to respiratory function. Plant Physiol 2010;152:747-61.
Tarantino D, Casagrande F, Soave C, Murgia I. Knocking out of the mitochondria AtFer4 ferritin does not alter response of Arabidopsis plants to abiotic stresses. J Plant Physiol 2010a;167:453-60.

Tarantino D, Santo N, Morandini P, Casagrande F, Braun HP, Heinemeyer J, et al AtFer4 ferritin is a determinant of iron homeostasis in Arabidopsis thaliana heterotrophic cells. J Plant Physiol 2010b;167:1598-605.

Thimm O, Essigmann B, Kloska S, Altmann T, Buckhout TJ. Response of Arabidopsis to iron deficiency stress as revealed by microarray analysis. Plant Physiol 2001; 127:1030-43.

Tiffin LO. Iron translocation. I. Plant culture, exudate sampling, iron-citrate analysis. Plant Physiol 1966;41:510-4.

Tomasi N, Weisskopf L, Renella G, Landi L, Pinton R, Varanini Z, et al. Flavonoids of white lupin roots participate in phosphorus mobilization from soil. Soil Biol Biochem 2008:40:1971-4.

Vigani G, Chittò A, De Nisi P, Zocchi G. cDNA-AFLP analysis reveals a set of new genes differentially expressed in response to Fe deficiency in cucumber (Cucumis sativus L.) root apexes. Biol Plant; in press.

Vigani G, Maffi D, Zocchi G. Iron availability affects the function of mitochondria in cucumber root. New Phytol 2009;182:127-36.

Vigani G, Zocchi G. Effect of Fe deficiency on mitochondrial alternative NAD(P)H dehydrogenases in cucumber roots. J Plant Physiol 2010;167:666-9.

Vigani G, Zocchi G. The fate and the role of mitochondria in Fe-deficient roots of Strategy I plants. Plant Signal Behav 2009;5:375-9.

von Wiren N, Klair S, Bansal S, Briat JF, Khodr H, Shioiri T, et al. Nicotianamine chelates both FeIII and FeII. Implications for metal transport in plants. Plant Physiol 1999;119:1107-14.

Wang BL, Tang XY, Cheng LY, Zhang AZ, Zhang WH, Zhang FS, et al. Nitric oxide is involved in phosphorus deficiency induced cluster-root development and citrate exudation in white lupin. New Phytol 2010;187:1112-23.

Waters BM, Blevins DG, Eide DJ. Characterization of FRO1, a pea ferricchelate reductase involved in root iron acquisition. Plant Physiol 2002;129:85-94.

Waters BM, Lucena C, Romera FJ, Jester GG, Wynn AN, Rojas CL, et al. Ethylene involvement in the regulation of $\mathrm{H}^{+}$-ATPase CsHA1 gene and of the new isolated ferric reductase CSFRO1 and iron transporter CsIRT1 genes in cucumber plants. Plant Physiol Biochem 2007;45:293-301.

Welkie GW, Heckmat-Shoar H, Miller GW. Responses of pepper (Capsicum annum L.) plants to iron deficiency: solution $\mathrm{pH}$ and riboflavin. In: van Beusichem $\mathrm{M}$ editor. Plant nutrition-physiology and applications. Dordrecht: Kluwer; 1990. p. 207-11.

Welkie GW, Miller GW. Plant iron uptake physiology by nonsiderophore systems. In: Barton LL, Hemming BC, editors. Iron chelation in plants and soil microorganisms. New York: Academic Press; 1993. p. 345-70.

Wendehenne D, Durner J, Klessig DF. Nitric oxide: a new player in plant signalling and defence responses. Curr Opin Plant Biol 2004;7:449-55.

Zancani M, Peresson C, Biroccio A, Federeci G, Urbani A, Murgia I, et al. Evidence for the presence of ferritin in plant mitochondria. Eur J Biochem 2004;271: 3657-64.

Zocchi G. Metabolic changes in iron-stressed dicotyledonous plants. In: Barton LL, Abadía J, editors. Iron nutrition in plants and rhizospheric microorganisms. Dordrecht, The Netherlands: Springer; 2006. p. 359-70.

Zocchi G, De Nisi P, Dell'Orto M, Espen L, Marino Gallina P. Iron deficiency differently affects metabolic responses in soybean roots. J Exp Bot 2007;58:993-1000. 